DOI: $10.15421 / 272016$

УДК 101:37.01

\author{
А. М. Шаталович, И. В. Шаталович
}

Днипровский нацииональный университет имени Олеся Гончара, Днипро, Украина

\title{
МЕТАФИЗИКА ОБРАЗОВАНИЯ: СУЩНОСТЬ И ПЕРВОПРИЧИНЫ
}

\author{
E-mail: shatdnu@gmail.com \\ ORCID: 0000-0001-7388-9216 \\ E-mail: shatdnu@gmail.com \\ ORCID: 0000-0001-8679-9228
}

Аннотация. Исследование образования метафизическим методом является актуальной задачей, которая не имеет четкой системной постановки в современной литературе. Цель статьи - эксплицировать сущность и первопричины образования, так как анализ научной, справочной, учебно-методической и законодательной литературы выявил неполноту существующих дефиниций образования с точки зрения метафизического измерения. Выявлено, что более полно раскрыть сущность образования позволяет одновременное обращение к категориям становления и бытия (образование как процесс и результат) с учетом праксеологического акцента (образование как деятельность). Природа образования раскрывается благодаря антропному (с акцентом на жизненный опыт человека и развитие личности), социальному (с акцентом на социализации и коммуникации) и культурному (образование понимают, как окультуривание и трансляцию культуры) основаниям. Установлено, что в современной литературе более полно разработаны формальная (формальные, неформальные и информальные виды обучения и воспитания) и целевая (в наиболее общем виде: учиться быть) первопричины. Субстратные и действующие первопричины образования требуют дальнейшей разработки.

Ключевые слова: метафизика, сущность, образование, философия образования.

\section{О. М. Шаталович, І. В. Шаталович}

\author{
Дніпровський національний університет імені Олеся Гончара, Дніпро, Україна
}

\section{МЕТАФІЗИКА ОСВІТИ: СУТНІСТЬ І ПЕРШОПРИЧИНИ}

Анотація. Дослідження освіти метафізичним методом є актуальним завданням, яке не має чіткої системної постановки в сучасній літературі. Мета статmі - експлікувати сутність і першопричини освіти, так як аналіз наукової, довідкової, навчально-методичної та законодавчої літератури виявив неповноту існуючих дефініцій освіти з точки зору метафізичного виміру. Виявлено, що більш повно розкрити сутність освіти дозволяє одночасне звернення до категорій становлення і буття (освіта як процес і результат) 3 урахуванням праксеологічного акценту (освіта як діяльність). Природа освіти розкривається завдяки антропним (з акцентом на життєвий досвід людини і розвиток особистості), соціальним (з акцентом на соціалізації і комунікації) і культурним (освіту розуміють як окультурення і трансляцію культури) підвалинам. Встановлено, що в сучасній літературі більш повно розроблено формальну (формальні, неформальні та інформальні види навчання і виховання) і цільову (в найбільш загальному вигляді: вчитися бути) першопричини. Субстратні та діючі першопричини освіти вимагають подальшої розробки.

Ключові слова: метафізика, сутність, освіта, філософія освіти. 


\title{
Oleksandr Shatalovych, Inna Shatalovych
}

\author{
Oles Honchar Dnipro National University, Dnipro, Ukraine
}

\section{METAPHYSICS OF EDUCATION: ESSENCE AND FIRST PRINCIPLES}

\begin{abstract}
The study of education by the metaphysical method is an important topic, but often does not have a clear system statement. The analysis of scientific, reference, educational, methodological and legislative literature revealed the incompleteness of the existing definitions of education from the point of view of the metaphysical dimension. The purpose of the article is to explicate the essential features and first principles of education. The author of the article revealed that researchers often reveal the essence of education due to the category of being (education as a result) and the category of becoming (education as a process). If the authors of the definitions use both of these categories, then such formulations are more successful. In addition to these categories, the category of activity is important for clarifying the essence of education. Education is not only a process (activity, development, change), but also an activity (active and expedient change and transformation), which includes the goal, means, result, and the process of activity itself. The concept of a system is another traditional option that helps to reveal the essence of education. However, in relation to modern education, the term system (in a broad sense) is not quite appropriate, since education today is not a centralized system, but a decentralized sphere of educational services.

The author of the article explicates the nature of education. Education has three bases: anthropic, social, and cultural. Authors who define education and use an anthropic basis focus on a person's life experience or personal development. Authors who prefer a social basis when defining education emphasize socialization or communication. If the authors base the definition of education on the basis of culture, they understand education as the cultivation and translation of culture. In its full meaning, education is a combination of anthropic, social and cultural foundations and represents the activities of the individual and society for the preservation and development of culture. In addition to the essential features and nature of education, the author explicates the formal (formal, non-formal, informal learning and upbringing) and target (learning to be is the main goal of education) first causes of education. The matter and efficient first causes need further development. Movement arises as a dialectical resolution of the contradiction between opportunities and needs, opportunities and aspirations of a person and society. The needs of self-improvement and self-preservation (of a person, society, culture) also claim to be the efficient causes of education.
\end{abstract}

Keywords: metaphysics, essence, education, philosophy of education.

Введение. Среди многочисленных исследований по философии образования тема метафизики образования (в четкой постановке) представлена не столь многочисленными работами, что тем не менее не уменьшает ее важности и актуальности. Так, по мнению Н. Рыбакова [16], метафизика представляет собой фундаментальное проникновение в недра любого процесса, способствуя постижению его смысла. Именно поэтому, с точки зрения исследователя, необходимо обратиться к метафизике для выявления общей картины образования как основы всех частных выводов о нем. О необходимости интеграции метафизики в философию образования писал исследователь Дж. Халдейн [9]. Современный исследователь А. Брук [4, p. 48-49] также настаивает на необходимости вернуться к метафизике и перечитать ее заново. Он использует метафизический принцип как способ исследования онтологических основ деятельности по образованию и приходит к выводу, что первичным смыслом образования является формирование нашей человеческой идентичности.

Следует обратить внимание, что небольшое число работ, непосредственно посвященных метафизике образования, не является показательным, так как многие авторы, исследующие образование, имплицитно используют метафизический метод, но не раскрывают его потенциал в полной мере. Двигаясь в русле метафизических исследований, эксплицируем сущность и первопричины образования, акцентируемые в научной, справочной, учебно-методической и законодательной литературе, что будет являться целью данной статьи. 
Изложение основного материала. Среди признаков, которые позволяют прояснить сущность образования, в литературе можно встретить различные варианты. Согласно исследованию И. Серебрянской (проведенному на основании лексикографических, энциклопедических, научных и нормативных источников): «В українській мовній картині світу освіта передусім усвідомлюється як «процес» $(21 \%)$, «система» $(14 \%)$, рідше - «сфера», «процес і результат», «діяльність», «сукупність знань» (по 8 \%), «рівень знань» (5\%). Зафіксовано також інші семи: «навчання, виховання», «основа розвитку особистості, суспільства і держави», «сектор нематеріальної галузі», «організована й послідовна комунікація заради навченості», «писемність, грамотність», «поширення основ знання», «духовне обличчя», «захист проти сил, що знеособлюють людину», «розвиток особистості й формування громадянина», «соціальне явище», «соціальна цінність», «функція суспільства й держави стосовно громадян», «функція свідомого саморозвитку громадян», «результат», «дисципліна», «віддзеркалення життя народу», «індикатор сталого людського розвитку» (по $1,5 \%$ )» $[17$, с. 88$]$.

В первую очередь уточним в метафизическом ключе наиболее «популярные», согласно данного исследования, родовые понятия «процесс» и «система». Во-первых, акцент на понятии процесс хотя и возводит понимание образования к категории становления, но не учитывает инвариантных смыслов категории бытия. Более удачны, по нашему мнению, те определения, в которых авторы при выборе родовых понятий определения стараются опираться на обе указанные категории (и становления, и бытия). Например, образование - «процес і результат удосконалення здібностей і поведінки особистості, при якому вона досягає соціальної зрілості та індивідуального зростання» [10, с. 241]. Во-вторых, наряду с акцентированием процессуальных свойств образования важно подчеркивать его праксеологический (греч. praxis - действие) аспект. Так как образование - это не только процесс (развитие, изменение), но, прежде всего, деятельность (активное и целесообразное изменение и преобразование), которая включает в себя цель, средства, результат и сам процесс деятельности.

Рассмотрим еще один распространенный вариант родового понятия для определения образования - понятие система. Как подчеркивает Б. Гершунский [6, c. 40-45], в традиционном понимании, образование - это, несомненно, система. Система образовательных (государственных и негосударственных) учреждений, различающихся по самым разным параметрам, но, прежде всего, по уровню и профилю. Но, как справедливо отмечает исследователь, такое вертикально-горизонтальное многообразие образовательных учреждений само по себе еще не может служить основанием для придания образованию статуса системы. Система, как известно, это не просто множество объектов, но их взаимосвязанное множество. Именно в этом случае система приобретает интегративные, новые качества, не выводимые непосредственно из качеств входящих в систему компонентов и не являющиеся простой механической суммой качеств частей, образующих систему. В отношении же современного образования термин система (в широком значении) не совсем уместен. Так, как образование сегодня - это не столько централизованная система, сколько децентрализованная сфера образовательных услуг. Следовательно, соглашаясь с Б. Гершунским, от глобальных характеристик образования как системы целесообразнее перейти к более конкретным системным описаниям, имеющим отношение, прежде всего, к практической педагогической деятельности: «учебно-воспитательная система», «педагогическая система».

Продолжим рассмотрение сущности образования через обращение к категории

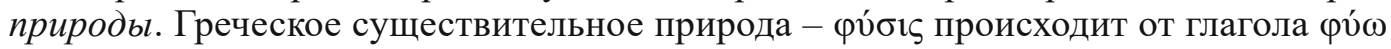
(«выращивать», «рождать», «производить на свет»). Кроме своего широкого значения (совокупность всего сущего), природа, как отмечает С. Месяц, означает сущность той или иной вещи. Согласно Аристотелю, фv́бıь связана с определенным пониманием бытия, а именно с таким, когда бытие истолковывается как начало. Быть началом, 
значит быть причиной чего-то иного - начинающегося, возникающего, становящегося [13, с. $346-348]$.

Природу образования в большинстве определений можно охарактеризовать посредством одной из таких первооснов: человек, общество, культура. Соответственно, образование выступает как специфический феномен человека, феномен социума, феномен культуры.

При обращении к первооснове «человек», авторы определений апеллируют к развитию (саморазвитию личности) или развитию жизненного опыта человека $[14$, c. 130]. Если автор определения апеллирует к первооснове «общество», то он, как правило, обращает внимание на вопросы социализации или коммуникации. Например, образование - «процесс педагогически организованной социализации, осуществляемой в интересах личности и общества» [2]. Или, «Освіта - організована й послідовна комунікація заради навченості. При цьому комунікація розглядається як взаємодія між певною кількістю осіб, що пов'язана з передаванням інформації» $[1$, c. 44]. То есть коммуникация, как средство взаимодействия, выступает маркером социума. Таким образом, природа образования раскрывается в данных определениях через приобщение к социуму или через взаимодействие членов социума.

В случае акцента на первооснове «культура» именно она служит основанием для образования. В таком случае образование выступает «окультуренням» [1, c. 44], или трансляцией культуры. Как подчеркивают Б. Бим-Бад и А. Петровский, в образовании непосредственное бытие человека соединяется с культурой, осмысляется и упорядочивается в системе художественных образов, нравственных категорий и научных понятий, социально одобряемых образцов поведения [2]. Данная связь культуры и образования не случайна. Известный философ С. И. Гессен [7] рассматривает образование как культуру личности, как процесс приобщения человека к культурным ценностям науки, искусства, морали, права. Как правильно отмечает С. В. Борисов, система образования издавна рассматривает себя посредником между личностью и культурой; школа, учитель, учебник заняты переводом с различных сложившихся в культуре общества языков на языки формирующихся индивидуальных культур [3, c. 19-20].

Следует подчеркнуть, что при формулировке определений образования необходимо придерживаться не взаимоисключения, а взаимодополнения указанных оснований, так как образование вырастает на пересечении всех трех выявленных оснований (антропного, социального и культурного) и представляет собою необходимое условие для деятельности личности и общества по сохранению и развитию материальной и духовной культуры.

Метафизическое измерение образования будет неполным без рассмотрения его формальных, субстратных, иелевых и действующих первопричин.

Среди перечисленных первопричин к наиболее разработанным в современной литературе можно отнести разве что формальную и целевую. С достаточной степенью четкости они имеют отражение в научной, учебной и законодательной литературе. Так, например, исследовательница О. Крашнева выделяет три цели образования: 1) обогащение обучающегося знаниями, привитие и развитие способностей ментального порядка; 2) подготовка личности к выполнению определенных профессиональных обязанностей; 3) воспитание в процессе обучения цивилизованных личностей [11, c. 13-14]. Согласно Закону Украины «Про освіту»: «Метою освіти є всебічний розвиток людини як особистості та найвищої цінності суспільства, iї талантів, інтелектуальних, творчих і фізичних здібностей, формування цінностей і необхідних для успішної самореалізації компетентностей, виховання відповідальних громадян, які здатні до свідомого суспільного вибору та спрямування своєї діяльності на користь іншим людям і суспільству, збагачення на цій основі інтелектуального, економічного, творчого, культурного потенціалу Українського народу, підвищення освітнього рівня громадян задля забезпечення сталого розвитку України та ії європейського вибору» [12]. Такой широкий перечень становится понятным в контексте главной цели образования: «учиться 
быть», которая прозвучала в докладе Э. Фора (ЮНЕСКО, 1972 г.). Как комментируют отечественные исследователи: «Освіта, яка в якості головної мети має «вчитися, щоб бути», постає вже не як освіта на все життя, а як освіта, протягом усього життя, тобто як освіта безперервна і така, що розвиває креативний потенціал особистості» [15, с. 185].

Не менее активно в современной литературе разрабатывается тема образования с точки зрения формальной причины, что также находит свое отражение в научной [8], учебной [1] и законодательной литературе [12, ст. 8-9], в частности, формальные, неформальные и информальные виды обучения и воспитания.

В то же время осмысление субстратной и движущей причин образования не имеют столь широкого распространения в современной литературе. Предпринимаемые попытки (например, И. Фомичева рассматривает механизм и движущие силы образовательновоспитательного процесса, исходя из возникновения и диалектического разрешения внешних и внутренних противоречий между возможностями и потребностями человека и общества [5]) требуют дальнейшей, более всесторонней разработки (возможно с акцентом на потребностях самосовершенствования и самосохранения человека, общества, культуры).

Выводы. Смысловое многообразие дефиниций образования в метафизическом измерении восходит к категориям бытия и становления, которые целесообразнее рассматривать вместе при формировании определения (например, образование как процесс и результат) с подчеркиванием праксеологического аспекта (образование как деятельность).

Природа образования (или первооснова, из которой оно вырастает) эксплицирована в качестве совокупности антропного, социального и культурного оснований, которые современные исследователи зачастую используют порознь, делая акцент или на жизненный опыт человека и развитие личности, или на социализацию и коммуникацию, или на окультуривание и трансляцию культуры. Указанная совокупность оснований требует переосмысления с точки зрения системного подхода.

Установлено, что целевые и формальные первопричины образования более полно разработаны в современной литературе, нежели субстратные и действующие первопричины, которые требуют дальнейшего осмысления.

\section{REFERENCES}

1. Baby'n, I. I., Bolyubash Ya. Ya., Garmash A. A. j in. (2011). Nacional'ny'j osvitnij glosarij: vy'shha osvita [National educational glossary: higher education]. Za red D. V. Tabachny'ka i V. G. Kremenya. K.: TOV «Vy’davny'chy’j dim «Pleyady'», 2011.100 s. (in Ukrainian).

2. Bim-Bad, B. M., Petrovskij, A. V. (1999). Obrazovanie. Rossijskaja pedagogicheskaja jenciklopedija [Education. Russian Pedagogical Encyclopedia]. V 2-h t. Glavnyj redaktor V. V. Davydov. Moskva. URL: http://www.otrok.ru/teach/enc/txt/15/page4.html (in Russian).

3. Borisov, S. V. (2016). Filosofija obrazovanija i nauki: metodicheskie rekomendacii [Philosophy of Education and Science: guidelines]. Cheljabinsk: Izd-vo Cheljab. gos. ped. un-ta, 97 s. (in Russian).

4. Brook, A. (2013). What is Education? Re-reading metaphysics in search of foundations. New Blackfriars, no. 94, pp. 32-49. doi:10.1111/j.1741-2005.2012.01503.x

5. Fomicheva, I. G. (2004). Filosofija obrazovanija: nekotorye podhody k problem [Philosophy of education: some approaches to the problem]. Novosibirsk: Izd-vo SO RAN. 242 s. (in Russian).

6. Gershunskij, B. S. (1998). Filosofija obrazovanija [Philosophy of Education]. Moskva: Flinta. 432 s. (in Russian).

7. Gessen, S. I. (1995). Osnovy pedagogiki. Vvedenie v prikladnuju filosofiju [Fundamentals of pedagogy: Introduction to the applied philosophy]. M.: Shkola-Press, 1995. 448 s. (in Russian).

8. Grehnev, V. S. (2019). Formy obrazovanija: filosofsko-metodologicheskie osnovanija ih opredelenija [Forms of education: philosophical and methodological bases of their definition]. Sovremennye problemy nauki i obrazovanija. № 2. URL: http://www.science-education.ru/article/view? id=28641(in Russian).

9. Haldane, J. (1989). Metaphysics in the Philosophy of Education. Journal of Philosophy of Education, no. 23: pp.171-183. doi:10.1111/j.1467-9752. 1989.tb00205.x 
10. Goncharenko, S. (1997). Ukrai'ns'kyj pedagogichnyj slovnyk [Ukrainian pedagogical dictionary]. K.: Lybid'. 375 s. (in Ukrainian).

11. Krashneva, O. E. (2005). Filosofija obrazovanija (social'no-filosofskij analiz predmetnoj oblasti) [Philosophy of education (socio-philosophical analysis of the subject area)]: dis. ... kand. filos. nauk. Rostov-na-Donu, 2005. 179 s. (in Russian).

12. Zakon Ukrai'ny. Pro osvitu [Law of Ukraine. About education]. Zakon vid 05.09.2017. № 2145VIII. (2017). Kyi'v. Verhovna Rada Ukrai'ny. 127 s. (in Ukrainian).

13. Mesjac, C. B. Priroda (2010). Novaja filosofskaja jenciklopedija [Nature. New Philosophical Encyclopedia]: v 4-h tt. T. 3. V.S. Stepin, G. Ju. Semigin (red.). M.: «Mysl'». S. 346-352. (in Russian).

14. Novikov, A. M. (2013). Pedagogika: slovar' sistemy osnovnyh ponjatij [Pedagogy: Dictionary of the System of Basic Concepts]. M.: Izdatel'skij centr IJeT. 268 s. (in Russian).

15. Filosofija osvity [Philosophy of education]. Andrushhenko V., Peredbors 'ka I. (red.). (2009). Kyi’v. Vyd-vo NPU imeni M. P. Dragomanova. 329 s. (in Ukrainian).

16. Rybakov, N. S. (2009). Metafizika obrazovanija v informacionnuju jepohu [Metaphysics of education in the Information Epoch.]. Filosofija obrazovanija. № 4 (29). S. 10-19. (in Russian).

17. Serebrjans 'ka, I. M. (2018). Osvita v Ukrai'ni: sposterezhennja kriz' pryzmu movnoi' kartyny svitu: monografija [Education in Ukraine: observation through the prism of the language picture of the world]. Harkiv. 2018. 416 s. (in Ukrainian).

Received 15.09.2020

Accepted 25.09.2020

DOI: $10.15421 / 272017$

УДК 168.74

\section{Марія-Катерина Павчук}

Кафедра філософії, Чернівецький національний університет імені Юрія Федьковича, Чернівиі, Украӥна

\section{НЕОПРАГМАТИЗМ РІЧАРДА РОРТІ В КОНТЕКСТІ ПРОБЛЕМАТИКИ СУЧАСНОЇ ФІЛОСОФІЇ НАУКИ}

E-mail: katyapavchuk@meta.ua

Анотація. У даній статті досліджено актуалізацію філософії неопрагматизму та її взаємозв'язок 3 лінгвістичною та аналітичною філософією.

Внесок до прагматичного поворота філософії вивчає, як ці різні дискурсивні стратегії пов'язані між собою і в чому полягає їх доречність до взаємозв'язку між прагматизмом і філософією в цілому. Філософія, за Рорті, як і культура загалом, $є$ не пошуком істини, а розмовою та комунікацією. Переорієнтація з пізнання та істини на розмову і комунікацію могла б створити основу для втілення в життя нового типу філософії, побудованої не на об’єктивності, а на іронії та солідарності. Головний позитив деконструктивістського проекту Рорті полягає у стимуляції філософів із табору раціоналістів вдосконалювати інструментарій, необхідний для вирішення нових конструктивних завдань. В історії філософії таким завжди був наслідок радикалістської романтичної критики. Лінгвістична філософія і неопрагматизм виявились напрямками, які, зародившись у межах сцієнтистського способу теоретизування, виявились цілком пристосованими до синтезу своїх ідей з побудуванням течій, які традиційно інтерпретують як антисцієнтистські. Це повною мірою стосується лінгвістичної філософії Л. Вітгенштейна і його послідовників, неопрагматистів У. Куайна, Д. Девідсона, М. Уайта, Р. Рорті та інших. Серед сучасних дослідників дану тему розробляли А. Ф. Грязнов, Ю. В. Жарких, У. Г. Труіта, І. С. Добронравова.

Ключові слова: неопрагматизм, комунікація, універсалії, сцієнтизм, раціональність, Річард Рорті. 